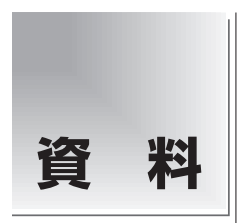

加藤豊大 ${ }^{1}$ 市川 肇 ${ }^{1}$ 三輪建太 ${ }^{2} \quad$ 奥田光一 ${ }^{3} \quad$ 澁谷孝行 $^{4} \quad$ 長木昭男 $^{5} \quad$ 對間博之 $^{6}$

\section{国内の核医学検查における追加撮像の実態調查}

論文受付

2019 年 6 月 14 日

論文受理

2019 年 12 月 4 日

Code No. 330

\author{
${ }^{1}$ 豊橋市民病院放射線技術室 \\ 2 国際医療福祉大学保健医療学部放射線・情報科学科 \\ ${ }^{3}$ 金沢医科大学自然科学領域 \\ ${ }^{4}$ 金沢大学医薬保健研究域保健学系医療科学領域量子医療技術学講座 \\ ${ }^{5}$ 倉敷中央病院放射線技術部 \\ ${ }^{6}$ 茨城県立医療大学保健医療学部放射線技術科学科
}

\section{緒 言}

近年のガンマカメラおよび positron emission tomography (PET) 装置の進歩は著しく, computed tomography $(\mathrm{CT})$ との複合装置の普及は $\mathrm{PET} / \mathrm{CT}$ 装置 の登場から急速に普及し, 今日では single photon emission computed tomography (SPECT) /CT 装置も 一般的になりつつある. 画像処理技術は, コンピュー 夕の高速化により逐次近似画像再構成法がほぼすべて
の施設で日常的に利用され, SPECTでは減弱補正, 散乱線補正，コリメー夕開口補正も一般的になった。 また, 一部では standardized uptake value(SUV)を利 用した定量画像や computer-assisted diagnosis (CAD) の利用も始まっている，同様にPETにおいては，装 置によって高分解能画像や呼吸同期収集，金属アーチ ファクト除去 (metal artifact reduction: MAR), 点応 答関数 (point spread function: PSF) を用いた分解能補

\title{
A Nationwide Survey on Additional Scan in Nuclear Medicine Imaging
}

Toyohiro Kato, ${ }^{1 *}$ Hajime Ichikawa, ${ }_{6}$ Kenta Miwa, ${ }^{2}$ Koichi Okuda, ${ }^{3}$ Takayuki Shibutani, ${ }^{4}$ Akio Nagaki, ${ }^{5}$ and Hiroyuki Tsushima ${ }^{6}$

${ }^{1}$ Department of Radiology, Toyohashi Municipal Hospital

${ }^{2}$ Department of Radiological Sciences, School of Health Science, International University of Health and Welfare

${ }^{3}$ Department of Physics, Kanazawa Medical University

${ }^{4}$ Department of Quantum Medical Technology, Faculty of Health Sciences, Kanazawa University

${ }^{5}$ Department of Radiological Technology, Kurashiki Central Hospital

${ }^{6}$ Department of Radiological Sciences, Ibaraki Prefectural University of Health Sciences

Received June 14, 2019; Revision accepted December 4, 2019

Code No. 330

\section{Summary}

The aim of the present study was to clarify the routine protocols and the frequency of added or omitted imaging on nuclear medicine imaging in Japan. A nationwide survey on routine protocols and current state of added or omitted imaging in major nuclear medicine imaging were performed for Japanese nuclear medicine technologist. The survey showed that the routine protocols were almost $100 \%$ fixed, some of the routine protocols were found to be useful and percentage of imaging techniques such as single photon emission computed tomography/computed tomography that increased patient burden and reduced through put were low. Furthermore, the survey showed that additional or omission imaging were frequently performed on bone scintigraphy and positron emission tomography and added or omitted judgements were often depend upon the rule of thumb by nuclear medicine technologist. In this study, we have concluded that the quality of examination and the diagnosis might depend on the knowledge of nuclear medicine technologist, performed added or omitted imaging.

Keywords: nuclear medicine imaging, routing protocol, evidence, additional scan, omission scan

*Corresponding author 
正などさまざまな撮像方法や画像再構成・補正方法を 容易に利用することが可能となった。

核医学検查は撮像時の異常所見やアーチファクトの 有無により, 通常行っている検査いわゆるルーチン検 査に対して診断能の向上を目的として撮像や画像処理 を追加することがしばしばある，例えば，骨シンチグ ラフィ(以下，骨シンチ)に扔けるSPECTまたは $\mathrm{SECT} / \mathrm{CT}$ の追加は診断能を向上させる ${ }^{1 \sim 9)}$, 心筋血 流シンチグラフィ(以下，心筋血流シンチ)に打けるコ リメータ開口補正機能付き ordered subset expectation maximization method (OSEM) 法の追加は病変部 の歪みや部分容積効果による影響を低減させる ${ }^{10 \sim 12)}$,

PETに扮ける呼吸同期収集の追加は病変の検出能を 向上させる ${ }^{13,14)}, \mathrm{MAR}$ の追加は金属アーチファクト が生じている部分の SUV の精度低下を改善する ${ }^{15,16)}$ などが報告されている。これらのように，撮像や画像 処理の追加は適切に行われることによって、ルーチン 検査のみでは得られなかった新たな診断価值が見出さ れることは少なくない. 一方で, 施設の検査状況に よっては患者一人に費すことができる検查時間が短く SPECT などの有用である追加撮像が困難である場合 や所有する装置によっては呼吸同期収集または MAR などの収集方法や画像処理が行えない場合も考えられ る.このように, 施設によって撮像の方法, 画像再構 成・処理方法, 出力画像が異なることが予想される.

核医学検查の実態調査は, 日本アイソトープ協会に よる全国の核医学実態調査 ${ }^{177}$ がある。この実態調査 では核医学検査の検査件数の推移や装置の種類掞よび 台数については把握できるものの, 撮像の方法, 回数, 出力画像については把握することができない，そのほ かに国内の検査内容について調査した報告はないた め，各施設がエビデンスに基づき正しく撮像されてい るかは明らかではない，厚生労働省の通達(医政発 0430 第 1 号)では診療放射線技師として読影の補助が 明記されており，施設によっては追加撮像または撮像 省略の判断を検查担当技師が行う場合も考えられ，検 查の質更に診断の結果が技師の知識に左右される可能 性がある.このような状況の中, 検査において撮像の 不足, あるいは過剩な追加撮像が行われていることが 懸念され, 診断目的に応じた検査プロトコルの確立が 早急に求められる。追加撮像または撮像省略の実態を 明らかにするためには，まず各施設のルーチン検査内 容を把握し, ルーチン検査に対して何を追加し, 何を 省略しているのかを調査する必要がある。更に，これ らの撮像内容や追加・省略に至るプロセスについてエ ビデンスを構築することが必要である.
そこで，われわれは国内の主な核医学検査における ルーチン検査の内容, および追加撮像または撮像省略 の頻度と判断基準についてアンケート調査し, それら の実態を明らかにすることを目的とした。

\section{1. 方 法}

アンケートは, 公益社団法人日本放射線技術学会の 会員を対象に同学会 webサイトで実施し, メールマ ガジンにてアンケートへの協力を要請した。なお，同 施設であっても個々の技師の撮像方法に差がある可能 性があるため, アンケート対象は診療放射線技師個人 とした、したがって、アンケート結果には 1 施設から 複数の回答を得る場合もあった。倫理的配慮のため, アンケートは回答者の自由意志で参加できるように し，回答をもって同意を得たことを同 web サイトに 掲示した。調查期間は 2017 年 10 月 4 日から 12 月 20 日までとし，アンケート内容は回答者の背景(施設形 態, 経験年数, 核医学専門技師の取得の有無, 装置の 種類), ルーチン検査の内容(ルーチン検査の有無, 撮 像方法, 画像再構成法, 画像処理 - 解析方法), 追加撮 像または撮像省略の実態 (追加撮像または撮像省略の 有無, 判断方法および根拠) とした (Table 1). 調査し た核医学検査は, 検查件数が多く追加撮像または撮像 省略が行われている頻度が高いと予想し, 以下のもの とした. ${ }^{99 \mathrm{~m}}$ Tc-hydroxy mathylene diphosphonate (HMDP), ${ }^{99 \mathrm{~m}} \mathrm{Tc}-\mathrm{mathylene}$ diphosphonate (MDP) を 用いた転移性骨腫瘍の診断目的の骨シンチ, ${ }^{99} \mathrm{~m} T \mathrm{~T}$-tetrofosmin (TF), ${ }^{99 \mathrm{~m}} \mathrm{Tc}$-sestamibi(MIBI) を用いた虚血 性心疾患の診断目的の心筋血流シンチ (以下, ${ }^{99 \mathrm{~m}} \mathrm{Tc}$ 心 筋血流シンチ), ${ }^{201} \mathrm{TlCl}$ を用いた虚血性心疾患の診断 目的の心筋血流シンチ (以下, ${ }^{201} \mathrm{Tl}$ 心筋血流シン チ), ${ }^{123}$ I-metaiodobenzylguanidine (MIBG)を用いた パーキンソン病またはレビー小体型認知症の診断目的 の心筋交感神経シンチグラフィ(以下, 心筋 MIBG シ ンチ), ${ }^{99 \mathrm{~m}} \mathrm{Tc}$-フチン酸, ${ }^{99 \mathrm{~m}} \mathrm{Tc} \mathrm{c}$ スズコロイドを用いた 乳がんにおけるセンチネルリンパ節の検索目的のセン チネルリンパ節シンチグラフィ（以下，センチネルリ ンパ節シンチ), ${ }^{18}$ F-Fluorodeoxyglucose を用いた悪性 腫瘍の診断目的の PET (以下, FDG-PET).

\section{2. 結 果}

\section{2-1 回答者の背景}

アンケート回答者数は 249 名であった。 回答者の施 設形態の割合は, 公的病院が最も多く36\%で, 次いで 民間病院 34\%, 大学病院 28\%, その他 2.4\%であった。 核医学経験年数の平均は 11.6 年であり, 回答者の 
Table 1 A survey with 27 questions geared towards the routine protocols of nuclear medicine imaging

\begin{tabular}{ll}
\hline \multicolumn{1}{c}{ Question } & \\
\hline Demogrphics & Option \\
Q1. Your place of medical institution & University hospital, Public hospital, Private hospital, Others \\
Q2. Experience in nuclear medicine tecnologist & Year \\
Q3. Possession of JBNMT & Yes or No \\
Q4. Equipment for ganma camera imaging & SPECT imaging systems, SPECT/CT imaging systems, Planar imaging \\
& systems, SPECT imaging systems with semiconductor detector, \\
Q5. Equipment for PET imaging & SPECT/CT imaging systems with semiconductor detector, Others \\
& PET imaging systems, PET/CT imaging systems, PET/MRI imaging \\
\end{tabular}

\section{Routine protocol} Bone scintigraphy

Q6. Existence of routine protocol

Q7. Image acquisition method

Q8. Image reconstruction method

Q9. Image correction method

Myocardial perfusion scintigraphy $\left({ }^{99} \mathrm{~m} \mathrm{Tc}\right.$ and $\left.{ }^{201} \mathrm{TI}\right)$

Q10. Existence of routine protocol

Q11. Image acquisition method

Q12. Image reconstruction method

Q13. Image correction method

Q14. Image analysis method

\section{MIBG scintigraphy}

Q15. Existence of routine protocol

Q16. Image acquisition method

Q17. Image reconstruction method

Q18. Image correction method

Q19. Image analysis method

\section{Sentinel lymph scintigraphy}

Q20. Existence of routine protocol

Q21. Image acquisition method

Q22. Position and direction for planar acquisition

\section{FDG-PET}

Q23. Scan ranges for early imaging

Q24. Implementation of delayed scan

Q25. Image reconstruction or correction method

\section{Additional or omission imaging}

Q26. Implementation of additional or omission scan

Q27. Judgment method and ground for additional or omission scan

\author{
Yes or No \\ Whole-body, Planar, SPECT, SPECT/CT \\ FBP, OSEM with RR, OSEM without RR \\ $\mathrm{AC}, \mathrm{SC}, \mathrm{ACSC}, \mathrm{ACSC}+\mathrm{NC}, \mathrm{NC}$
}

Yes or No

Planar, SPECT, SPECT/CT

FBP, OSEM with RR, OSEM without RR

$\mathrm{AC}, \mathrm{SC}, \mathrm{ACSC}, \mathrm{ACSC}+\mathrm{NC}, \mathrm{NC}$

ECG-gated image, Scoring, Phase analysis, CAD, Fusion of SPECT and coronaly CT images, Body cross-sectional images, Absolute quantitative analysis, Fusion of SPECT and CT images, Washout rate $\left({ }^{201} \mathrm{Tl}\right)$, Lung to heart ratio $\left({ }^{201} \mathrm{Tl}\right)$, Others

Yes or No

Planar, SPECT, SPECT/CT

FBP, OSEM with RR, OSEM without RR

$\mathrm{AC}, \mathrm{SC}, \mathrm{ACSC}, \mathrm{ACSC}+\mathrm{NC}, \mathrm{NC}$

Washout rate, CAD, QGS, QPS, Fusion of SPECT and CT images, Others

Yes or No

Planar, SPECT, SPECT/CT

Potition: Supine, Half supine, Upright, Direction: Anterior, Latelal, Oblique

Top: Scalp, Orbital, Neck, Bottom: Inguinal region, Femur, Knee, Tone Yes or No

AC, SC, PSF, TOF, Metal artifact reduction, High resolution image, Respiratory-gated image, Uncorrected image, Others

Yes or No

Method: Institutional agreement, Consultation with physician, Decision by technologist, Other, Ground: Literature, Rule of thumb, No ground, Others

SPECT: single photon emission computed tomography, CT: computed tomography, MRI: magnetic resonance imaging, FBP: filtered back projection, OSEM: ordered subset expectation, RR: resolution recovery, AC: attenuation correction, SC: scatter correction, NC: no correction, ECG: electro-cardiogram, MIBG: meta-iodobenzylguanidine, CAD: computer-assisted diagnosis, QGS: quantitative gate SPECT, QPS: quantitative perfusion SPECT, PSF: Point spread function, TOF: time of flight

$43 \%$ が 10 年以上核医学検査に携わっていた。また, 回答者の約半数の $47 \%$ が核医学専門技師を取得して いた。 ガンマカメラの種類は，SPECT 装置が74.6\%， SPECT/CT 装置が $46.6 \%$, 半導体検出器を搭載した SPECT 装置が $8.5 \%$, 半導体検出器を搭載した SPECT/CT 装置が0.8\%であった。 PET装置は,
$\mathrm{PET} / \mathrm{CT}$ 装置が 95.8\%，SPECT/PET複合装置を含 む PET 装置が $5.6 \%$, 半導体検出器を搭載した PET 装置が $0.7 \%$, PET/magnetic resonance imaging (MR) 装置が $0.7 \%$ であった，各検査のアンケート回答者数 は, 骨シンチで $230,{ }^{99 \mathrm{~m}} \mathrm{Tc}$ 心筋血流シンチで 178 と ${ }^{201} \mathrm{Tl}$ 心筋血流シンチで 174 , 心筋 $\mathrm{MIBG}$ シンチで 


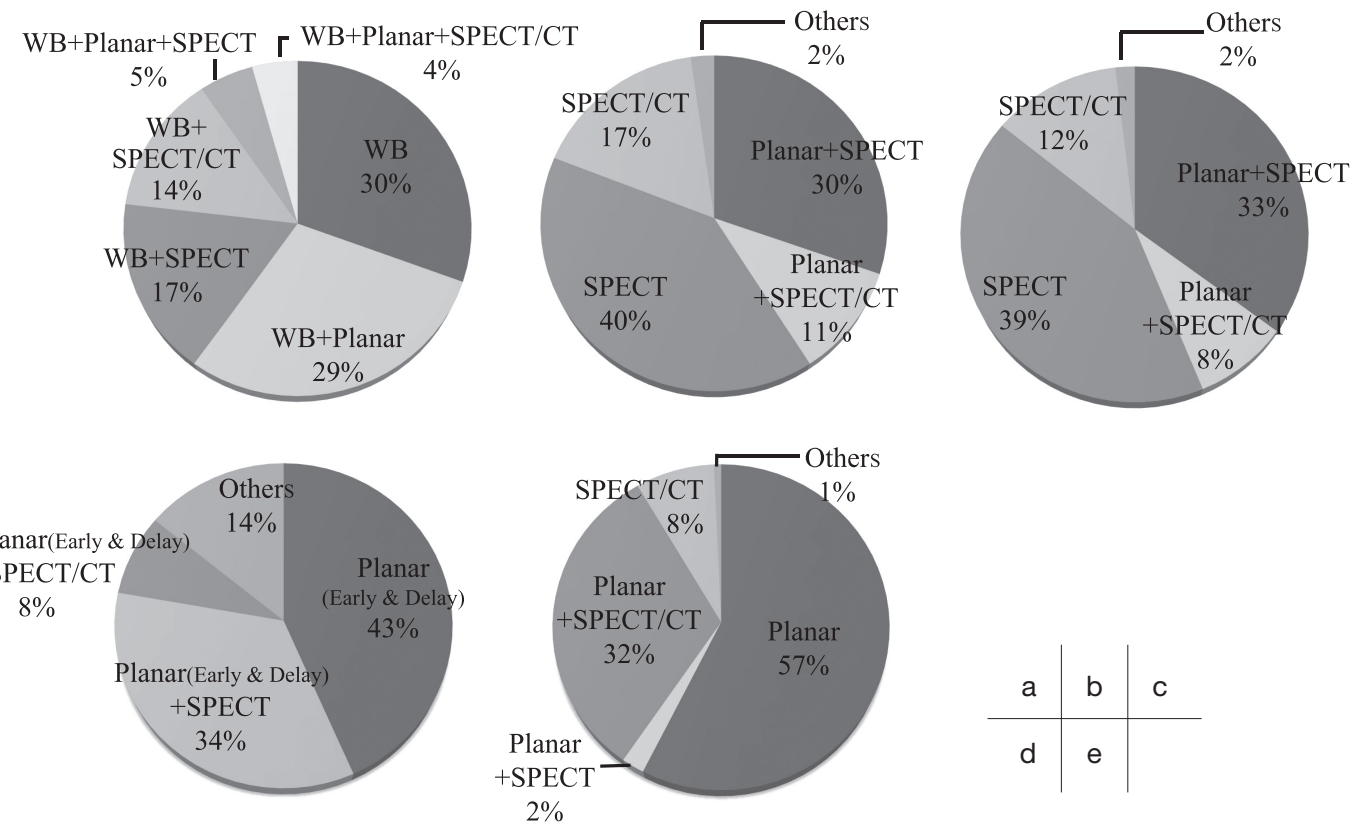

Fig. 1 Percentage of routine acquisition method with gamma camera imaging.

WB: Whole-body, SPECT: single photon emission computed tomography, CT: computed tomography (a) Bone scintigraphy, (b) Myocardial perfusion scintigraphy $\left({ }^{99 \mathrm{~m}} \mathrm{Tc}\right)$, (c) Myocardial perfusion scintigraphy $\left({ }^{201} \mathrm{Tl}\right)$, (d) MIBG scintigraphy $\left({ }^{123} \mathrm{I}\right)$, (e) Sentinel lymph scintigraphy

Table 2 Percentage of image reconstruction and correction method with Bone scintigraphy, Myocardial perfusion scintigraphy and MIBG scintigraphy

\begin{tabular}{|c|c|c|c|c|c|c|c|c|}
\hline & \multicolumn{8}{|c|}{ Percentage of response $(\%)$} \\
\hline & \multicolumn{3}{|c|}{ Image reconstraction method } & \multicolumn{5}{|c|}{ Correction method } \\
\hline & FBP & $\begin{array}{c}\text { OSEM } \\
\text { (with/without RR) }\end{array}$ & $\begin{array}{c}\text { FBP+OSEM } \\
\text { (with/without RR) }\end{array}$ & $\mathrm{NC}$ & $\mathrm{AC}$ & $\mathrm{SC}$ & ACSC & $\mathrm{ACSC}+\mathrm{NC}$ \\
\hline $\begin{array}{l}\text { Bone scintigraphy } \\
(\mathrm{n}=230)\end{array}$ & 7.4 & 62.2 & 0.9 & 22.9 & 4.8 & 6.0 & 29.9 & 1.8 \\
\hline $\begin{array}{l}\text { Myocardial perfusion scintigraphy }\left({ }^{99 \mathrm{~m}} \mathrm{Tc}\right) \\
(\mathrm{n}=178)\end{array}$ & 47.8 & 28.7 & 20.8 & 34.8 & 6.7 & 9.0 & 23.6 & 3.4 \\
\hline $\begin{array}{l}\text { Myocardial perfusion scintigraphy }\left({ }^{201} \mathrm{Tl}\right) \\
(\mathrm{n}=174)\end{array}$ & 59.2 & 22.4 & 14.9 & 36.2 & 8.0 & 9.8 & 14.4 & 3.4 \\
\hline $\begin{array}{l}\text { MIBG scintigraphy }\left({ }^{123} \mathrm{I}\right) \\
(\mathrm{n}=214)\end{array}$ & 25.7 & 18.7 & 4.2 & 26.6 & 2.3 & 7.0 & 0.0 & 0.0 \\
\hline
\end{tabular}

MIBG: meta-iodobenzylguanidine, FBP: filtered backprojection, OSEM: ordered subset expectation, RR: resolution recovery, NC: no correction, AC: attenuation correction, SC: scatter correction, ACSC: attenuation correction and scatter correction, ACSC+NC: attenuation correction, scatter correction and no correction

214, センチネルリンパ節シンチで 141, PET で 143 であった。

\section{2-2 ルーチン検査の内容}

ルーチン検査内容は，すべての検査において 100\% 決まっていたが, その撮像内容や出力画像は多岐に 渡った. Figure 1 に各ガンマカメライメージングに おけるルーチン撮像方法, Table 2 に骨シンチ, 心筋 血流シンチ, 心筋 MIBGにおける画像再構成法および 各種補正法, Table 3 に心筋血流シンチにおける画像 解析法, Table 4 に心筋 MIBG シンチにおける画像解
析法, Table 5 にセンチネルリンパ節シンチにおける プラナーの撮像方法を示した。また, Table 6 に FDG-PETにおける早期像の撮像範囲, Table 7 に FDG-PETにおける撮像方法および各種補正法を示 した。

骨シンチにおいて SPECT を撮像する割合は，全身 像と SPECT を撮像する割合 $(17 \%)$ と全身像とプラ ナーと SPECTを撮像する割合 (5\%)の合計 $22 \%$ で り，SPECT/CTを撮像する割合は全身像と SPECT/ CTを撮像する割合 $(14 \%)$ と全身像とプラナーと SPECT/CT を収集する割合 (4\%)の合計 $18 \%$ であっ 
Table 3 Percentage of image analysis method with Myocardial perfusion scintigraphy

\begin{tabular}{|c|c|c|}
\hline \multirow[b]{2}{*}{ Image analysis method } & \multicolumn{2}{|c|}{ Percentage of response $(\%)$} \\
\hline & $\begin{array}{c}{ }^{99}{ }_{\mathrm{m}} \mathrm{Tc} \\
(\mathrm{n}=178)\end{array}$ & $\begin{array}{c}{ }^{201} \mathrm{Tl} \\
(\mathrm{n}=174)\end{array}$ \\
\hline ECG-gating scan (e.g. EDV, ESV and LVEF) & 95.5 & 71.3 \\
\hline Scoring (e.g. SSS, SRS and SDS) & 58.4 & 56.3 \\
\hline Phase analysis & 45.5 & 28.7 \\
\hline CAD (e.g. ANN score) & 33.7 & 28.7 \\
\hline Fusion of SPECT and coronaly CT images & 15.2 & 8.0 \\
\hline $\begin{array}{l}\text { Body cross-sectional images } \\
\quad \text { (e.g. axial, coronal or sagittal image) }\end{array}$ & 8.4 & 11.5 \\
\hline Absolute quantitative analysis (e.g. MBF) & 6.7 & 4.6 \\
\hline Fusion of SPECT and CT images & 6.2 & 4.6 \\
\hline Washout rate & - & 56.3 \\
\hline Lung to heart ratio & - & 9.2 \\
\hline
\end{tabular}

ECG: electro-cardiogram, EDV: left ventricular end diastolic volume, ESV: left ventricular end systolic volume, LVEF: left ventricular ejection fraction, SSS: summed stress score, SRS: summed rest score: SDS: summed difference score, CAD: computer-assisted diagnosis, ANN: artificial neural network, SPECT: single photon emission computed tomography, CT: computed tomography, MBF: myocardial blood flow

Table 4 Percentage of image analysis method with MIBG scintigraphy

\begin{tabular}{lc}
\hline \multicolumn{1}{c}{ Image analysis method } & $\begin{array}{c}\text { Percentage of response }(\%) \\
(\mathrm{n}=214)\end{array}$ \\
\hline Washout rate & 46.7 \\
CAD (e.g. Smart MIBG) & 43.9 \\
Quantitative Gate SPECT (QGS) & 7.9 \\
Quantitative Perfusion SPECT (QPS) & 4.7 \\
Fusion of SPECT and CT images & 2.3 \\
Others & 6.5 \\
\hline
\end{tabular}

Table 5 Percentage of planar acquisition method with Sentinel lymph scintigraphy

\begin{tabular}{lccc}
\hline \hline \multirow{3}{*}{ Position } & \multicolumn{3}{c}{$\begin{array}{c}\text { Percentage of response }(\%)(\mathrm{n}=141) \\
\text { Direction }\end{array}$} \\
\cline { 2 - 4 } & Anterior & Latelal & Oblique \\
\hline Supine & 83.7 & 17.0 & 39.0 \\
Oblique & 17.7 & 0.0 & 17.7 \\
Upright & 0.7 & 0.0 & 0.7 \\
\hline
\end{tabular}

CAD: computer-assisted diagnosis, MIBG: meta-iodobenzylguanidine, SPECT: single photon emission computed tomography, CT: computed tomography, QGS: quantitative gate SPECT, QPS: quantitative perfusion SPECT

Table 6 Scan ranges for early scan with FDG-PET

\begin{tabular}{lc}
\hline \hline \multicolumn{1}{c}{ Field of view } & $\begin{array}{c}\text { Percentage of response }(\%) \\
(\mathrm{n}=139)\end{array}$ \\
\hline TOP & \\
Scalp & 88.5 \\
Orbital & 3.6 \\
Neck & 5.0 \\
Bottom & \\
Inguinal region & 47.5 \\
Femur & 46.0 \\
Knee & 11.5 \\
Tone & 16.5 \\
\hline
\end{tabular}

た(Fig. 1a)，画像再構成法および各種補正法におい ては，コリメータ開口補正機能付き OSEM 法と減弱· 散乱線補正を行う割合が，それぞれ $62.2 \%$ と $29.9 \%$ で あり， ${ }^{99} \mathrm{~m} \mathrm{Tc}$ 心筋血流シンチ， ${ }^{201} \mathrm{Tl}$ 心筋血流シンチ, 心筋 MIBG シンチより高い割合であった(Table

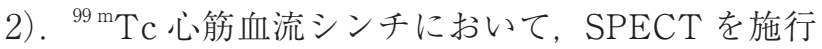

Table 7 Percentage of image acquisition and correction method with FDG-PET

\begin{tabular}{lc}
\hline \hline \multicolumn{1}{c}{ Correction or acqisition method } & $\begin{array}{c}\text { Percentage of response }(\%) \\
(\mathrm{n}=139)\end{array}$ \\
\hline AC & 91.4 \\
SC & 80.6 \\
PSF & 48.9 \\
TOF & 40.3 \\
NC & 28.1 \\
Respiratory gated image & 10.1 \\
High resolution image & 7.2 \\
Metal artifact reduction & 7.2 \\
Others & 2.2 \\
\hline
\end{tabular}

$\mathrm{AC}$ : attenuation correction, $\mathrm{SC}$ : scatter correction, $\mathrm{NC}$ : no correction

する割合は 70\%で SPECT/CTを施行する割合は 28\%であり，SPECT に比べSPECT/CT の施行割合 が低かった（Fig. 1b)。画像再構成法および各種補 正法においては, filtered back projection(FBP)法を用 い減弱・散乱線補正を行わない割合が高かった(Table 2)。これらは, ${ }^{201} \mathrm{Tl}$ 心筋血流シンチにおいても同様な 
Table 8 Judgment method and ground for additional or omission scan

\begin{tabular}{|c|c|c|c|c|c|c|c|c|}
\hline & \multicolumn{8}{|c|}{ Percentage of response $(\%)$} \\
\hline & \multicolumn{4}{|c|}{ Judgement method } & \multicolumn{4}{|c|}{ Judgement ground } \\
\hline & $\begin{array}{c}\text { Institutional } \\
\text { agreement }\end{array}$ & $\begin{array}{c}\text { Consultation } \\
\text { with physician }\end{array}$ & $\begin{array}{l}\text { Decision by } \\
\text { technologist }\end{array}$ & Other & Literature & $\begin{array}{l}\text { Rule of } \\
\text { thumb }\end{array}$ & No basis & Others \\
\hline $\begin{array}{l}\text { Bone scintigraphy } \\
(\mathrm{n}=195)\end{array}$ & 16.4 & 27.7 & 76.9 & 0.0 & 7.7 & 58.5 & 20.5 & 18.5 \\
\hline $\begin{array}{l}\text { Myocardial perfusion scintigraphy }(\mathrm{Tc}) \\
(\mathrm{n}=32)\end{array}$ & 18.8 & 37.5 & 56.3 & 0.0 & 18.8 & 25.0 & 12.5 & 15.6 \\
\hline $\begin{array}{l}\text { Myocardial perfusion scintigraphy }(\mathrm{Tl}) \\
(\mathrm{n}=24)\end{array}$ & 16.7 & 79.2 & 29.2 & 4.2 & 20.8 & 25.0 & 16.7 & 8.3 \\
\hline $\begin{array}{l}\text { MIBG scintigraphy }\left({ }^{123} \mathrm{I}\right) \\
(\mathrm{n}=38)\end{array}$ & 26.3 & 28.9 & 44.7 & 0.0 & 10.5 & 36.8 & 23.7 & 23.7 \\
\hline $\begin{array}{l}\text { Sentinel lymph scintigraphy } \\
(\mathrm{n}=40)\end{array}$ & 26.3 & 39.5 & 42.1 & 0.0 & 2.5 & 40.1 & 12.5 & 2.6 \\
\hline $\begin{array}{l}\text { FDG-PET } \\
(\mathrm{n}=98)\end{array}$ & 31.6 & 53.1 & 49.0 & 2.0 & 10.2 & 53.1 & 11.2 & 17.3 \\
\hline
\end{tabular}

傾向であった。画像解析法においては, ${ }^{201} \mathrm{Tl}$ 心筋血流 シンチは ${ }^{99} \mathrm{~m} T \mathrm{TC}$ 心筋血流シンチと同様の画像解析に加 え, washout rate やlung to heart ratio が算出されて いた (Table 3)。心筋 MIBG シンチにおいて，早期と 後期のプラナのみを撮像する割合は 43\%であり, プラ ナとSPECTまたはSPECT/CTを撮像する割合は 42\%であった (Fig. 1d)。画像解析法においては, washout rate と CAD の使用割合が，それぞれ 46.7\% と 43.9\%であった(Table 4)。 センチネルリンパ節シ ンチのルーチン検査内容において, SPECT/CT は回 答者数の $40 \%$ が施行しており，骨シンチ， ${ }^{99 \mathrm{~m}} \mathrm{Tc}$ 心筋 血流シンチ, ${ }^{201} \mathrm{Tl}$ 心筋血流シンチ, 心筋 MIBG と比べ 高い割合であった(Fig. 1e)。プラナの撮像体位およ び方向においては，仰臥位正面のプラナの施行割合が 83.7\% であった(Table 5). FDG-PET のルーチン検査 内容において, 早期像の撮像範囲の上端を「頭頂」と する割合が $88.5 \%$ ，下端を「鼠径部」あるいは「大腿中 部」までとする割合がそれぞれ 47.5\%と 46.0\%であっ た (Table 6)。ルーチンで胸腹部またはその都度の範 囲を決定して後期像を撮像する割合は $58.3 \%$ あっす た。撮像方法と各種補正においては，減弱補正，散乱 線補正の施行割合がそれぞれ $91.4 \%$ と $80.6 \%, P S F$ 補 正，TOF 収集の施行割合がそれぞれ $48.9 \%$ と 40.3\%， 高分解能画像，呼吸同期収集，MAR の施行割合は 10\%程度であった(Table 7)。

\section{2-3 追加撮像または撮像省略の実態}

ルーチン検査に対して撮像を追加または省略する割 合は，骨シンチで $84.8 \%,{ }^{99} \mathrm{~m} T \mathrm{Tc}$ 心筋血流シンチで 18.0\%， ${ }^{201} \mathrm{Tl}$ 心筋血流シンチで 13.8\%，心筋 MIBG シ ンチで $17.8 \%$ ， センチネルリンパ節シンチで $28.4 \%$, FDG-PET で70.5\%であった。 Table 8 に追加撮像お
よび撮像省略の判断方法および根拠を示した。追加撮 像および撮像省略の判断方法は, ${ }^{201} \mathrm{Tl}$ 心筋血流シンチ と FDG-PET 以外のすべての検査で「担当技師に委ね られている」という回答割合が他の回答に比べ最も高 く，その根拠はすべての検査において「経験則」とい う回答割合が他の回答に比べ最も高かった(Table 8).

\section{3. 考 察}

国内の核医学検査におけるルーチン検査内容と追加 撮像または撮像省略の実態を明らかにするため，骨シ ンチ, ${ }^{99 \mathrm{~m}} \mathrm{Tc}$ 心筋血流シンチ, ${ }^{201} \mathrm{Tl}$ 心筋血流シンチ, 心筋 MIBG シンチ，センチネルリンパ節シンチ， FDG-PET におけるルーチン検査内容およびルーチン 検査に対する追加撮像または撮像省略についてアン ケート調査した。六つの核医学検査の内容は, すべて ルーチン化されていることが明らかになったが，各検 査のルーチン撮像内容は多岐に渡った。

骨シンチは，ルーチン検査におけるSPECT または SPECT/CT の撮像割合がそれぞれ $22 \%$ と $18 \%$ あ り，SPECTまたはSPECT/CT 装置の所有割合(それ ぞれ 74.6\%と 46.6\%)に比べ低い傾向であった。骨シ ンチにおいて全身像にSPECT や SPECT/CT を追加 すると, 前立腺がん, 乳がん, 肺がん, 春椎病変にお いて, 感度・特異度・陽陰性的中率が向上する ${ }^{1 \sim 6)}$, あ るいは良悪性診断に有効 ${ }^{7-9)}$ との報告がされている。 一方で，CT 撮影による被ばく線量が $1.88 \mathrm{mGy} / \mathrm{bed}$

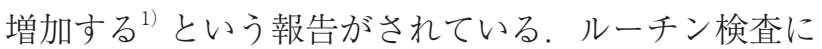
おける SPECT またはSPECT/CT の施行は, 上記の 特定のがんに対して診断能あるいは診断精度の向上が 期待できると考えられるが，CT 撮影による被ばくを 上回る利益があるかどうか慎重に判断しているため, 所有割合に対し，施行割合が低かったのではないかと 
考える. また, 骨シンチは他の検査に比べ画像再構成 法にコリメータ開口補正機能付き OSEM 法を用い, 減弱・散乱線補正を加える頻度が高かった。 OSEM 法 は, 被写体内に扔ける $\gamma$ 線の減弱・散乱, コリメー夕開 口径に扮ける空間分解能の低下に対して各補正パラ メー夕を画像再構成アルゴリズムに組み込み補正でき るため, 定量精度の向上が期待できる。骨シンチは, SPECT 定量画像の研究や開発, 臨床応用が進んでお $り^{18,19)}$ ，より精度の高い SUV 解析を行うため OSEM 法やそれに組み込むことができる減弱・散乱線補正の 利用頻度が高いと考えられる。

${ }^{99} \mathrm{~m} T \mathrm{c}$ 心筋血流シンチと ${ }^{201} \mathrm{Tl}$ 心筋血流シンチは, SPECT に比べSPECT/CT の施行割合が少ない傾向 にあった。また，画像再構成法に未だ FBP 法を用い， 各種補正を加える頻度が少ない傾向にあった。筋血 流シンチにおいて SPECT/CT を用いることで, CT 画像による冠動脈の石灰化の評価 ${ }^{20,21)}$ や予期せぬ病変 の検出 ${ }^{22)}$, CT 画像を用いた減弱・散乱線補正の利用 により冠動脈疾患検出の特異度の改善 ${ }^{23}$. 24) や病変部の コントラスト向上 ${ }^{25)}$ する利点があり，その有用性に関 する報告は多い。一方で, SPECT/CT の施行には, $\mathrm{CT}$ と SPECT の呼吸位相の違いからミスアライメン トによるアーチファクトが生じる ${ }^{26)}$ ，CT 画像を用い た減弱補正により前壁側の偽陽性率が上昇する ${ }^{27)}$, CT 画像を用いた減弱補正に関する有用性がまだ確立 していない27) との報告がされている。ルーチン検査 に扮ける SPECT/CT の利用は, CT 画像による新た な診断価值や画質改善を期待することができると考え るが, SPECT/CT 特有のアーチファクトや減弱補正 エラーが生じるため, その施行割合が少なかったので はないかと考えられる。画像再構成法に扮いては OSEM 法を用いることで, FBP 法で問題となる高力 ウント領域からのストリークアーチファクトや低カウ ント領域に扮ける $\mathrm{S} / \mathrm{N}$ を改善する ${ }^{28,29)}$, 更に OSEM 法にコリメー夕開口補正を組み込み部分容積効果を改 善することによって, 病変部と正常心筋のコントラス トが向上する ${ }^{10)}$, 病変部の歪みが回避11) できる, small heart の解析時に問題となる心室駆出率の過大評価の 影響を低減させる ${ }^{12)}$ と報告がされている。従来より， 心筋血流シンチにおいてはFBP 法で再構成した画像 を用いており，読影についても FBP 法での診断実績 が長い。したがって, OSEM 法やコリメー夕開口補正 機能付き OSEM 法についての有用性は多くあるが, FBP 法と異なる画像の読影についての経験が至しい ため, それらの画像再構成法が利用されていないので はないかと考えられる。また, ${ }^{201} \mathrm{~T} 1$ 心筋血流シンチ
は9 $\mathrm{m}$ Tc 心筋血流シンチに比べ, washout rate やlung to heart ratioが行われていた. Washout rateには冠 動脈の多肢病変や高度狭窄の補助指標としての有用 性 ${ }^{30}$-32), lung to heart ratio には, 冠動脈の多肢病変の 診断 ${ }^{33-35)}$ や病態の重症度・予後評価 ${ }^{36-38)}$ に有用との 報告がされている。 ${ }^{201} \mathrm{~T} 1$ 心筋血流シンチにおいて ルーチン検査でプラナ像を撮像している施設は, これ らの追加解析により診断精度の向上を目的としている と考えられる。

心筋 MIBG シンチは, 早期像と後期像のプラナ像の み撮像する割合とプラナ像に SPECT を撮像する割合 が同等であり，画像解析法に washout rate や CAD の 使用頻度が高い傾向にあった。心筋 MIBG シンチに おけるプラナの撮像は, 早期と後期のプラナ像の H/ $\mathrm{M}$ や washout rate を算出することで，アルッハイ マー病とレビー小体型認知症の鑑別診断 ${ }^{39-43)} や$ SPECT の撮像により心筋への MIBG 集積の限局的な 欠損の評価に有用 ${ }^{44)}$ とする報告がされている。また， $\mathrm{H} / \mathrm{M}$ 解析時に関心領域の設定を半自動化するソフト ウェア (Smart MIBG)の利用によって, 施設間やコリ メータ間差を補正し， H/M を標準化できる ${ }^{45,46)} と の$ 報告がされている。筋 MIBG シンチは，H/M によ る集積低下の診断が確立しその診断に有用な CAD が 開発されているため, ルーチン検査での SPECT を施 行する施設としない施設に分かれたと考えられる。

センチネルリンパ節シンチに拈いては, 他の検査と 比較して SPECT/CT が最も高い割合 (40\%)で行われ ていた。 センチネルリンパ節シンチは SPECT/CT の 利用により, リンパ節の同定率や位置関係の把握が容 易になる ${ }^{47.48)}$ との報告がされている。 センチネルリン パ節シンチは，放射性医薬品が主にリンパ節に集積す ることから, 他の検査と比較して SPECT 像のみで解 剖学的な位置関係を把握することが困難である. SPECT/CT は CT によって解剖学的な情報を同時に 取得できるため, センチネルリンパ節シンチは他検査 に比べ SPECT/CT の施行割合が高いと考えられる. また，プラナ像の撮像体位および方向は，ほとんど (83.7\%)が仰臥位正面であった。 センチネルリンパ節 シンチに抒いて, 仰臥位正面のプラナ像単体のリンパ 節の検出率は低く多方向からの撮像が必要 ${ }^{49,50)}$ である ため，斜位や座位 ${ }^{49}$, 50)によって注射部位とセンチネル リンパ節の位置を遠ざけ, リンパ節の検出能の改善が 得られてきた。センチネルリンパ節シンチにおいて斜 位や座位などの撮像法は, リンパ節の検出能を改善さ せるための補助的な役割として有用であると考える が, SPECT/CT の撮像により，その施行割合が低 
かったのではないかと考えられる。

FDG-PET においては, 早期像の撮像範囲を頭頂か ら鼠径部あるいは大腿中部とする回答が最も高く, 下 肢まで撮像する割合は低い傾向であった，FDG-PET においては，悪性リンパ腫や悪性黒色腫等の全身性病 変を呈す疾患に対して頭頂から下肢抹梢まで撮像する ことにより，治療方針が変わった ${ }^{51,52)}$ との報告がされ ている，全身性の疾患や病変の有無は事前の CT や他 の画像検查によって判明していることが多いこと, 更 に撮影範囲の延長によりスループットの低下や CT 撮 影による被ばく線量の増加が伴うため, ルーチン検査 で下肢まで撮像する割合が低いと考えられる。また,

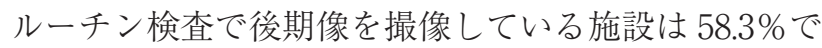
あり, 約半数は後期像を撮像していなかった. FDGPET における後期像の追加は, 腫瘍とバックグラウ ンドのコントラストが上昇することによって病変検出 の感度が改善 ${ }^{53-57)}$ する, あるいは良悪性の判断に有 用 ${ }^{58-60)}$ とされる報告が多くあった。ルーチン検査に おける後期像の撮像は, 病変の検出感度の改善や良悪 性判断に有用であると考えるが, 撮像回数の増加によ るスループットの低下，患者の拘束時間の延長， CT 撮影による被ばく線量の増加が懸念されるため, ルー チンで実施する施設としない施設に分かれたと考えら れる。 また, 各種補正・撮像方法には, 高分解能画像, 呼吸同期収集，MARの新しい技術の利用頻度が低い 傾向にあった. FDG-PET において呼吸同期収集や長 時間撮像を行うことにより肝臟への転移性病変の検出 能が向上する ${ }^{18,19)}$, MARを行うことにより金属アー チファクト部分のSUV の精度低下を改善できる ${ }^{20,21)}$, 高分解能画像を追加することにより小さな病変 $(<11 \mathrm{~mm})$ の SUV 精度の向上 ${ }^{61)}$ やリンパ節の検出に 有効 ${ }^{62)}$ との報告がされている. FDG-PET において, 呼吸同期收集, MAR, 高分解能画像を利用することに より病変の検出能や SUV 精度の向上が改善が期待で きると考えるが，装置によってはその撮像方法や機能 が利用できなかったり，診断可能な $\mathrm{S} / \mathrm{N}$ を担保する ためには撮像時間延長を要するため, 利用頻度が低く なったと考える。

追加撮像または撮像省略の頻度は, 骨シンチと FDG-PET で高く，その他の検査では追加撮像または 撮像省略がほとんど行われていなかった。また，その 判断は,「施設の決まりがある」より「検査担当技師に 委ねられている」の割合が高く，その根拠の多くは 「経験則」であるものが多くみられた。当初の予想通 り核医学検査の追加撮像または撮像省略の判断は, 検 查担当技師に委ねられている場合が多く施設内でもそ
の判断方法にばらつきがあると予想され，検査の質が 技師の知識に左右される可能性があると考えられる.

本研究では, 国内の主な核医学検査におけるルーチ ン検査の内容, および追加撮像または撮像省略の頻度 と判断基準についてアンケート調査し，それらの実態 を報告することを目的とした，よって，本調查内で示 した結果の中で使用頻度が高い撮像法や画像出力が必 ずしも最適であるかどうかはわからない。これらを明 らかにするためには, 最低限ルーチン検査で示す情報 やどのようなときに何の撮像や画像出力を追加または 省略すべきかを今後の研究で検証することが必要であ ると考える、しかしながら, 本研究によって各疾患あ るいは個々の患者に適した追加撮像または撮像省略を 系統的に行うためのエビデンスの構築の第一歩となる ことを切望する。

\section{4. 結 語}

核医学検査の中で, 追加撮像または撮像省略の頻度 が高いと予想した骨シンチ, ${ }^{99 \mathrm{~m}} \mathrm{Tc}$ 心筋血流シン チ, ${ }^{201} \mathrm{Tl}$ 心筋血流シンチ, 心筋 MIBG シンチ, センチ ネルリンパ節シンチ, FDG-PET についてのルーチン 検査内容および追加撮像または撮像省略の実態の把握 に向けてアンケート調查を行った。ルーチン検査はす べての施設で決まっており, SPECTやSPECT/CT など診断に有用とされる撮像法や新しい画像再構成 法・技術の利用頻度が少ないことが明らかになった。

また, 追加撮像や撮像省略の判断は検査担当技師に委 ねられている場合が多くその根拠は経験則であったた め, 検査の質や診断の結果が追加撮像または撮像省略 を行う技師の知識に左右される可能性があると考えら れた。各検査において, 疾患に応じた適切な撮像や画 像出力が行われることを切望する。

\section{謝 辞}

本研究に際しアンケート調査にご協力いただいた施 設の皆様に感謝申し上げます。

なお，本論文の要旨は第 46 回日本放射線技術学会 秋季大会 (2018 年, 仙台)にて発表した。

本研究は日本放射線技術学会より平成 29,30 年度 学術調査班研究助成を受けて行った。

\section{利益相反}

筆頭著者および共著者全員に開示すべき利益相反は ない. 
1) Palmedo H, Marx C, Ebert A, et al. Whole-body SPECT/CT for bone scintigraphy: diagnostic value and effect on patient management in oncological patients. Eur J Nucl Med Mol Imaging 2014; 41(1): 59-67.

2) Even-Sapir E, Metser U, Mishani E, et al. The detection of bone metastases in patients with high-risk prostate cancer: $99 \mathrm{mTc}-$ MDP Planar bone scintigraphy, single- and multi-field-of-view SPECT, 18F-fluoride PET, and 18F-fluoride PET/CT. J Nucl Med 2006; 47(2): 287-297.

3) Iqbal B, Currie GM, Wheat JM, et al. The incremental value of SPECT/CT in characterizing solitary spine lesions. J Nucl Med Technol 2011; 39(3): 201-207.

4) Schirrmeister H, Glatting G, Hetzel J, et al. Prospective evaluation of the clinical value of planar bone scans, SPECT, and (18)F-labeled NaF PET in newly diagnosed lung cancer. J Nucl Med 2001; 42(12): 1800-1804.

5) Strobel K, Burger C, Seifert B, et al. Characterization of focal bone lesions in the axial skeleton: performance of planar bone scintigraphy compared with SPECT and SPECT fused with CT. AJR Am J Roentgenol 2007; 188(5): W467-W474.

6) Horger M, Eschmann SM, Pfannenberg C, et al. Evaluation of combined transmission and emission tomography for classification of skeletal lesions. AJR Am J Roentgenol 2004; 183(3): 655-661.

7) Even-Sapir E, Martin RH, Barnes DC, et al. Role of SPECT in differentiating malignant from benign lesions in the lower thoracic and lumbar vertebrae. Radiology 1993; 187(1): 193198.

8) Delpassand ES, Garcia JR, Bhadkamkar V, et al. Value of SPECT imaging of the thoracolumbar spine in cancer patients. Clin Nucl Med 1995; 20(12): 1047-1051.

9) Love C, Din AS, Tomas MB, et al. Radionuclide bone imaging: an illustrative review. Radiographics 2003; 23(2): 341-358.

10）冨口静二. SPECT/CT 時代の新しい 3 次元画像再構成法 (Astonish). Medix 2008; 48: 25-30.

11) Römer W1, Reichel N, Vija HA, et al. Vija, et al. Isotropic reconstruction of SPECT data using OSEM3D: correlation with CT. Acad Radiol 2006; 13(4): 496-502.

12) Yoneyama $\mathrm{H}$, Nakajima $\mathrm{K}$, Okuda $\mathrm{K}$, et al. Reducing the smallheart effect in pediatric gated myocardial perfusion singlephoton emission computed tomography. J Nucl Cardiol 2017; 24(4): 1378-1388.

13) Crivellaro C, De Ponti E, Elisei F, et al. Added diagnostic value of respiratory-gated 4D 18F-FDG PET/CT in the detection of liver lesions: a multicenter study. Eur J Nucl Med Mol Imaging 2018; 45(1): 102-109.

14) Revheim ME, Haugvik SP, Johnsrud K, et al. Respiratory gated and prolonged acquisition 18F-FDG PET improve preoperative assessment of colorectal liver metastases. Acta Radiol 2015; 56 (4): 397-403.

15) Harnish R, Prevrhal S, Alavi A, et al. The effect of metal artefact reduction on CT-based attenuation correction for PET imaging in the vicinity of metallic hip implants: a phantom study. Ann Nucl Med 2014; 28(6): 540-550.

16) van der Vos CS, Arens AIJ, Hamill JJ, et al. Metal artifact reduction of CT scans to improve PET/CT. J Nucl Med 2017; 58(11): 1867-1872.

17）日本アイソトープ協会医学・薬学部会 全国核医学診療実
態調査専門委員会. 第 8 回全国核医学診療実態調査報告 書. RADIOISOTOPES. 2018; 67(7): 339-387.

18) Zeintl J, Vija AH, Yahil A, et al. Quantitative accuracy of clinical $99 \mathrm{mTc}$ SPECT/CT using ordered-subset expectation maximization with 3-dimensional resolution recovery, attenuation, and scatter correction. J Nucl Med 2010; 51(6): 921-928.

19）中西哲也. 新たな SPECT 画像再構成技術「xSPECT」. 日 放技誌 2015; 62(3): 228-231.

20) Einstein AJ, Johnson LL, Bokhari S, et al. Agreement of visual estimation of coronary artery calcium from low-dose CT attenuation correction scans in hybrid PET/CT and SPECT/CT with standard Agatston score. J Am Coll Cardiol 2010; 56(23): 1914-1921.

21) Schepis $T$, Gaemperli $O$, Koepfli $P$, et al. Use of coronary calcium score scans from stand-alone multislice computed tomography for attenuation correction of myocardial perfusion SPECT. Eur J Nucl Med Mol Imaging 2007; 34(1): 11-19.

22) Goetze S, Pannu HK, Wahl RL. Clinically significant abnormal findings on the "nondiagnostic" CT portion of low-amperageCT attenuation-corrected myocardial perfusion SPECT/CT studies. J Nucl Med 2006; 47(8): 1312-1318.

23) Utsunomiya $\mathrm{D}$, Tomiguchi $\mathrm{S}$, Shiraishi $\mathrm{S}$, et al. Initial experience with X-ray $\mathrm{CT}$ based attenuation correction in myocardial perfusion SPECT imaging using a combined SPECT/CT system. Ann Nucl Med 2005; 19(6): 485-489.

24) Sharma P, Patel CD, Karunanithi S, et al. Comparative accuracy of CT attenuation-corrected and non-attenuation-corrected SPECT myocardial perfusion imaging. Clin Nucl Med 2012; 37 (4): 332-338.

26) Verberne HJ, Acampa W, Anagnostopoulos C, et al. EANM procedural guidelines for radionuclide myocardial perfusion imaging with SPECT and SPECT/CT: 2015 revision. Eur J Nucl Med Mol Imaging 2015; 42(12): 1929-1940.

27）玉木長良, 日下部きよ子, 汲田伸一郎, 他. 循環器病の診 断と治療に関するガイドライン (2009 年度合同研究班報 告) 心臟核医学検査ガイドライン (2010 年改訂版). http:// www.j-circ.or.jp/guideline/pdf/JCS2010tamaki.h.pdf(cited 2012.10.12)

28）柳沢正道. 心筋 SPECT における定量化と標準化. 日放 技学誌 2004; 60(5): 666-675.

29）中田智明, 市川和弘, 大堀克己, 他. 統計的な画像再構成 法の臨床応用への可能性 2. OS-EM 法の心筋 SPECT へ の応用。日本医放会誌 2000; 60(7): 16-19.

30) Bateman TM, Maddahi J, Gray RJ, et al. Diffuse slow washout of myocardial thallium-201: a new scintigraphic indicator of extensive coronary artery disease. J Am Coll Cardiol 1984; 4 (1): 55-64.

31) Koskinen M, Pöyhönen L, Seppänen S. Thallium-201 washout in coronary artery disease using SPECT - a comparison with coronary angiography. Eur J Nucl Med 1987; 12(12): 609-612.

32) Yamada M, Chikamori $T$, Doi $Y$, et al. Negative washout rate of myocardial thallium-201-a specific marker for high grade coronary artery narrowing. Jpn Circ J 1992; 56(10): 975-982.

33) Boucher CA, Zir LM, Beller GA, et al. Increased lung uptake of thallium-201 during exercise myocardial imaging: clinical, hemodynamic and angiographic implications in patients with coronary artery disease. Am J Cardiol 1980; 46(2): 189-196.

34) Matoh F, Tawarahara K, Mikami N, et al. [Usefulness of lung 
and right ventricular thallium-201 uptake during single photon emission computed tomography in exercise testing of patients with coronary artery disease]. J Cardiol 2005; 46(4): 131-140 (in Japanese).

35) Georgoulias P, Tsougos I, Valotassiou V, et al. Long-term prognostic value of early poststress $(99 \mathrm{~m})$ Tc-tetrofosmin lung uptake during exercise (SPECT) myocardial perfusion imaging. Eur J Nucl Med Mol Imaging 2010; 37(4): 789-798.

36) Daou D, Coaguila C, Delahaye N, et al. Discordance between exercise SPECT lung Tl-201 uptake and left ventricular transient ischemic dilation in patients with CAD. J Nucl Cardiol 2004; 11(1): 53-61.

37) Hansen CL, Cen P, Sanchez B, et al. Comparison of pulmonary uptake with transient cavity dilation after dipyridamole Tl-201 perfusion imaging. J Nucl Cardiol 2002; 9(1): 47-51.

38) Sanders GP, Pinto DS, Parker JA, et al. Increased resting Tl201 lung-to-heart ratio is associated with invasively determined measures of left ventricular dysfunction, extent of coronary artery disease, and resting myocardial perfusion abnormalities. J Nucl Cardiol 2003; 10(2): 140-147.

39) Sawada H, Oeda T, Yamamoto K, et al. Diagnostic accuracy of cardiac metaiodobenzylguanidine scintigraphy in Parkinson disease. Eur J Neurol 2009; 16(2): 174-182.

40) Nagamachi S, Wakamatsu H, Kiyohara S, et al. Usefulness of rCBF analysis in diagnosing Parkinson's disease: supplemental role with MIBG myocardial scintigraphy. Ann Nucl Med 2008; 22(7): 557-564.

41) Kashihara K, Ohno M, Kawada S, et al. Reduced cardiac uptake and enhanced washout of 123I-MIBG in pure autonomic failure occurs conjointly with Parkinson's disease and dementia with Lewy bodies. J Nucl Med 2006; 47(7): 1099-1101.

42) Nagayama $H$, Hamamoto $M$, Ueda $M$, et al. Reliability of MIBG myocardial scintigraphy in the diagnosis of Parkinson's disease. J Neurol Neurosurg Psychiatry 2005; 76(2): 249-251.

43) Satoh A, Serita T, Seto M, et al. Loss of 123I-MIBG uptake by the heart in Parkinson's disease: assessment of cardiac sympathetic denervation and diagnostic value. J Nucl Med 1999; 40(3): 371-375.

44) Reinhardt MJ, Jüngling FD, Krause TM, et al. Scintigraphic differentiation between two forms of primary dysautonomia early after onset of autonomic dysfunction: value of cardiac and pulmonary iodine-123 MIBG uptake. Eur J Nucl Med 2000; 27 (5): 595-600

45) Okuda K, Nakajima K, Hosoya $T$, et al. Semi-automated algorithm for calculating heart-to-mediastinum ratio in cardiac Iodine-123 MIBG imaging. J Nucl Cardiol 2011; 18(1): 82-89.

46) Nakajima $K$, Okuda $K$, Matsuo $S$, et al. Standardization of metaiodobenzylguanidine heart to mediastinum ratio using a calibration phantom: effects of correction on normal databases and a multicentre study. Eur J Nucl Med Mol Imaging 2012; 39 (1): $113-119$

47) van der Ploeg IM, Olmos RA, Kroon BB, et al. The hidden sentinel node and SPECT/CT in breast cancer patients. Eur J Nucl Med Mol Imaging 2009; 36(1): 6-11.

48) Kraft O, Havel M. Sentinel lymph nodes and planar scintigraphy and SPECT/CT in various types of tumours. Estimation of some factors influencing detection success. Nucl
Med Rev Cent East Eur 2013; 16(1): 17-25.

49）市原裕紀, 小野口昌久, 日吉和久, 他. 乳がんセンチネル リンパ節シンチグラフィにおける半仰臥位正面像撮像体 位の有用性. 日放技学誌 2012; 68(4): 461-467.

50) Tsushima H, Takayama T, Kizu H, et al. Advantages of upright position imaging with medium-energy collimator for sentinel node lymphoscintigraphy in breast cancer patients. Ann Nucl Med 2007; 21(2): 123-128.

51) Sebro R, Mari-Aparici C, Hernandez-Pampaloni M. Value of true whole-body FDG-PET/CT scanning protocol in oncology: optimization of its use based on primary diagnosis. Acta Radiol 2013; 54(5): 534-539.

52) Osman MM, Chaar BT, Muzaffar R, et al. 18F-FDG PET/CT of patients with cancer: comparison of whole-body and limited whole-body technique. AJR Am J Roentgenol 2010; 195(6): 1397-1403.

53) Kubota K, Itoh M, Ozaki K, et al. Advantage of delayed wholebody FDG-PET imaging for tumour detection. Eur J Nucl Med 2001; 28(6): 696-703.

54) Higashiyama A, Komori $T$, Juri $H$, et al. Detectability of residual invasive bladder cancer in delayed 18F-FDG PET imaging with oral hydration using $500 \mathrm{~mL}$ of water and voiding-refilling. Ann Nucl Med 2018; 32(8): 561-567.

55) Lee JW, Kim SK, Lee SM, et al. Detection of hepatic metastases using dual-time-point FDG PET/CT scans in patients with colorectal cancer. Mol Imaging Biol 2011; 13(3): 565-572.

56) Arena V, Skanjeti A, Casoni R, et al. Dual-phase FDG-PET: delayed acquisition improves hepatic detectability of pathological uptake. Radiol Med 2008; 113(6): 875-886.

57) Hassler S, Hubele F, Constantinesco A, et al. Comparing respiratory gated with delayed scans in the detection of colorectal carcinoma hepatic and pulmonary metastases with 18F-FDG PET-CT. Clin Nucl Med 2014; 39(1): e7-e13.

58) Chang CY, Chang $\mathrm{CP}$, Shih $\mathrm{CC}$, et al. Added value of dualtime-point 18F-FDG PET/CT with delayed imaging for detecting aortic graft infection: an observational study. Medicine (Baltimore) 2015; 94(27): e1124.

59) Hustinx R, Smith RJ, Benard F, et al. Dual time point fluorine18 fluorodeoxyglucose positron emission tomography: a potential method to differentiate malignancy from inflammation and normal tissue in the head and neck. Eur J Nucl Med 1999; 26(10): 1345-1348.

60) Nakamoto $Y$, Higashi T, Sakahara H, et al. Delayed (18)Ffluoro-2-deoxy-D-glucose positron emission tomography scan for differentiation between malignant and benign lesions in the pancreas. Cancer 2000; 89(12): 2547-2554.

61) Koopman D, van Dalen JA, Lagerweij MC, et al. Improving the detection of small lesions using a state-of-the-art time-of-flight $\mathrm{PET} / \mathrm{CT}$ system and small-voxel reconstructions. J Nucl Med Technol 2015; 43(1): 21-27.

62) Li CY, Klohr S, Sadick H, et al. Effect of time-of-flight technique on the diagnostic performance of 18F-FDG PET/CT for assessment of lymph node metastases in head and neck squamous cell carcinoma. J Nucl Med Technol 2014; 42(3): $181-187$ 